\title{
Experimental investigation of the ultra-fine smash and separation of
}

\section{Shenfu semi-coke}

\author{
Zhao Shi-yong ${ }^{1, a^{*}}$, Wu Pei-pei ${ }^{1}$, Xu Jie ${ }^{2}$, Li xin² ${ }^{2}$ Zhang Sheng-jun², Long \\ Jiang $^{3}$
}

${ }^{1}$ College of Chemistry \& Chemical Engineering, Xi'an University of Science and Technology, Xi'an 710054, China

${ }^{2}$ Shanxi coal and Chemical Technology Institute CO., Ltd, Xi'an 710070, China

${ }^{3}$ Key Laboratory of Coal Resources Exploration and Comprehensive Utilization, Ministry of Land and Resources, Xi'an 710054, China

azhaoshiyong9@163.com

Keywords: Shenfu semi-coke; Impact crusher; Ultra-fine smash; Separation

Abstract: In order to investigate the effect of ultra-fine smash on the separation results of Shenfu semi-coke, the impact crusher was used to explore the relation between the degree of dissociation and the particle size and ash content. Additionally, the operating parameters of separation device of impact crusher was analyzed by the orthogonal experiment method and then it was optimized. The result of particle size analysis and oil absorption measurement to the ultra-fine smash of semi-coke reveals that both the ash content and oil absorption decrease with the increase of particle size, which indicates that the minerals of semi-coke are enriched in the fine fraction and the surface area of semi-coke ratio is increased after the ultra-fine smash. The proportion of ash content is $5.81 \%$, the $\mathrm{d}_{97}$ is $82.09 \mu \mathrm{m}$ and the productive rate is $22.67 \%$, respectively, while keeping the air inlet half-open, the speed of crusher $2900 \mathrm{r} / \mathrm{min}$ and the speed of classifier $700 \mathrm{r} / \mathrm{min}$. In conclusion, the experimental results reveal that the volume of air inlet, the speed of crusher and the speed of classifier take the dominant effect on the particle size and purification of Shenfu semi-coke, moreover, the impact crusher has an extra impact of separation while smashing the ultra-fine of the semi-coke.

\section{Introduction}

Shenfu semi-coke is based on the high quality of coal resources, which has been a new product of coal chemical industry and has been the pillar industry of the local economy ${ }^{[1-3]}$. The technology of ultra-fine smash has rapidly developed in recent years and relevant researches have been carried out by some scholars ${ }^{[4]}$. $\mathrm{Wu}^{[5]}$ invented an integrated equipment and successfully obtained the over-low ash content $(<1.5 \%)$ Taixi anthracite.

The impact crusher plays a significant effect on the ultra-fine smash of non-metallic minerals ${ }^{[6]}$, which can not only ultra-fine-mashes but purifies the minerals through the validation of massive experiments and field practices. Through experiment, Jiang et al. ${ }^{[8]}$ showed that the physical structure and flammability of ultra-fine smash changed dramatically. However, few previous scholars have done the research related to ultra-fine smash of semi-coke, therefore, we judge the work is meaningful and valuable. 
Through the ultra-fine smash of semi-coke, we expect to dissociate the organic matter and minerals, in addition, take the work of reducing the ash content, then obtain the semi-coke and refined coke with low ash content, which contributes to the utilization of semi-coke and draws a remarkable and meaningful research value.

\section{Experimental investigation}

\section{Characteristic of the raw material}

The raw material of the experiment is the pyrolytic produced semi-coke with the vertical heater in Shenfu, where the industrial analysis and elemental analysis are established in Table 1 and the particle size are stated in Table 2.

Table 1 Industrial analysis and elemental analysis

\begin{tabular}{cccccccccc}
\hline Sample & \multicolumn{3}{c}{ Industrial analysis (\%) } & \multicolumn{4}{c}{ Elemental analysis (\%) } \\
\hline \multirow{2}{*}{ Semi-coke } & $\mathrm{M}_{\mathrm{ad}}$ & $\mathrm{A}_{\mathrm{ad}}$ & $\mathrm{V}_{\text {daf }}$ & $\mathrm{FC}_{\mathrm{ad}}$ & $\mathrm{C}_{\mathrm{d}}$ & $\mathrm{H}_{\mathrm{d}}$ & $\mathrm{N}_{\mathrm{d}}$ & $\mathrm{O}_{\mathrm{d}}$ & $\mathrm{S}_{\mathrm{t}, \mathrm{d}}$ \\
\cline { 2 - 26 } & 2.23 & 10.99 & 3.80 & 84.24 & 79.56 & 1.75 & 5.17 & 0.33 & 0.20 \\
\hline
\end{tabular}

Table 1 reveals that the raw semi-coke is in low ash content, low volatile and low sulfur while in high fixed carbon content. And Table 2 shows that the dominate particle size is $3-6 \mathrm{~mm}$ with $43.34 \%$ occupation. In addition, the ash content of semi-coke increase with the decreasing particle size.

Table 2 Particle analysis of raw semi-coke

\begin{tabular}{ccccc}
\hline \multirow{2}{*}{$\begin{array}{c}\text { Particle size } \\
(\mathrm{mm})\end{array}$} & $\begin{array}{c}\text { Productivity } \\
(\%)\end{array}$ & $\begin{array}{c}\text { Ash content } \\
(\%)\end{array}$ & \multicolumn{2}{c}{ Productivity (\%) } \\
\cline { 4 - 5 } & 12.10 & 8.98 & $\begin{array}{c}\text { Positive } \\
\text { accumulation }\end{array}$ & $\begin{array}{c}\text { Negative } \\
\text { accumulation }\end{array}$ \\
\hline$>6$ & 43.34 & 9.77 & 12.10 & 100.00 \\
$6-3$ & 23.09 & 10.43 & 55.44 & 87.90 \\
$3-1$ & 9.55 & 13.57 & 78.53 & 44.56 \\
$1-0.5$ & 11.92 & 16.48 & 88.08 & 21.47 \\
$<0.5$ & 100.00 & 10.99 & 100.00 & 11.92 \\
Total & & - & - \\
\hline
\end{tabular}

Mineral constitution and disseminated characteristic analysis

Light slice made by semi-coke powder and observe the disseminated state of minerals in semi-coke, which illustrated in Figure 1.

It can be seem from Fig. 1 that the semi-coke mainly contains clay minerals and carbonate minerals, also tiny pyrites. However, the carbonate minerals translated to oxides as the development of pyrolysis. Its disseminated characteristics can be concluded as: (1) Inlaid aggregate submits to the micro fine crystal structure and distributes in the relatively large hole and resembles to the flowing amorphous state, also shows a slight protuberance with severely extinction; (2) the clay minerals distributes in the cell lumen or hole of organic matter with the state of particle and dispersion; (3) the tiny pyrites distributes in the organic matter of coal with the state of particle and dispersion.
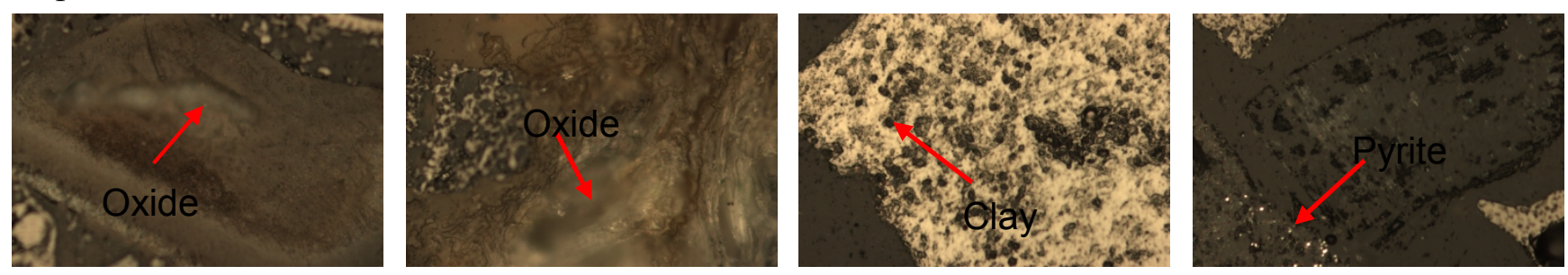

Figure 1 Microscopic photos of semi-coke $(\times 500)$ 


\section{Experimental equipment}

The CM-41 compact crush and classification system invented by the non-metal research institute in Xian-yang, China, is used to do the semi-coke experiment. Its working principle is: smashing the raw material and then absorbed into the classifier along with the airflow of main air blower. In the classifier, small particle materials can get into the dust catcher through the classified impeller while the big particle materials restricted and eventually gathered as the Product 3 (refined coke), and the product gathered by dust catcher named Product 4. The discharging particle size can be controlled by controlling the speed of crusher and classifier in the above period. Below the crusher there are two discharge gates, the product gathered from them are called Product 1 and Product 2, respectively. Fig. 2 schemes the working process of impact smash and classification system.

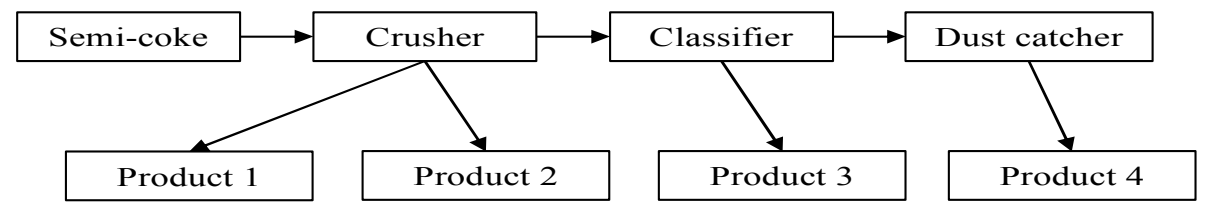

Figure 2 Flow sheet of the impact smash and classification system

\section{Impact smash and classification of semi-coke}

In order to investigate the influence of impact smash and classification system to the classification of Shenfu semi-coke, we designs a typical contrast experiment showed in Table 3. Besides the parameters of speed of smash, speed of classifier and the air volume of blower, the feeding coal and amount are $1.4 \mathrm{~kg} / \mathrm{min}$ and $3 \mathrm{~kg}$, respectively. The condition of removing inclusion port is half-open and the air supply outlet is totally open.

\section{Detection and characterization}

Table 3 Concrete conditions of the experiment

\begin{tabular}{cccc}
\hline NO. & $\begin{array}{c}\text { Speed of the crusher A } \\
\left(\mathrm{r} \cdot \mathrm{s}^{-1}\right)\end{array}$ & $\begin{array}{c}\text { Speed of the classifier B } \\
\left(\mathrm{r} \cdot \mathrm{s}^{-1}\right)\end{array}$ & $\begin{array}{c}\text { Air volume of the blower C } \\
\left(\mathrm{m}^{3} \cdot \mathrm{min}^{-1}\right)\end{array}$ \\
\hline 1 & 2900 & 700 & $0.5 Q$ \\
2 & 2900 & 800 & $0.75 Q$ \\
3 & 2800 & 800 & $0.5 Q$ \\
4 & 2800 & 600 & $0.75 Q$ \\
5 & 2700 & 600 & $Q$ \\
6 & 2700 & 700 & 0 \\
\hline
\end{tabular}

Based on the criterion of particle size measurement, we used the LS230 laser particle size analyzer invented by the Beckman Instrument (USA) to measure the particle size of the optimized specimens. In addition, in order to characterize the change of specific surface area of coke powder, we also detected the oil absorption of the specimens. The reagent of the detection is DBP and the main equipment are a micro burette (the minimum division value is 0.01 $\mathrm{cm} 3$ ), an analytical balance ( the precision is $1 \mathrm{mg}$ ), a glass plate $(170 \mathrm{~mm} \times 140 \mathrm{~mm} \times 4 \mathrm{~mm})$ and a glass rod (the diameter is $7-8 \mathrm{~mm}$, the length is about $300 \mathrm{~mm}$ ). 


\section{Results and Discussion}

\section{Results of the orthogonal experiment}

Table 4 Results of the orthogonal experiment

\begin{tabular}{ccccccccc}
\hline & \multicolumn{2}{c}{ Product 1 } & \multicolumn{2}{c}{ Product 2 } & \multicolumn{2}{c}{ Product 3 } & \multicolumn{2}{c}{ Product 4 } \\
\cline { 2 - 9 } NO. & $\begin{array}{c}\text { Productivity } \\
(\mathrm{kg})\end{array}$ & $\begin{array}{c}\text { Ash } \\
\text { content } \\
(\%)\end{array}$ & $\begin{array}{c}\text { Productivity } \\
(\mathrm{kg})\end{array}$ & $\begin{array}{c}\text { Ash } \\
\text { content } \\
(\%)\end{array}$ & $\begin{array}{c}\text { Productivity } \\
(\mathrm{kg})\end{array}$ & $\begin{array}{c}\text { Ash } \\
\text { content } \\
(\%)\end{array}$ & $\begin{array}{c}\text { Productivity } \\
(\mathrm{kg})\end{array}$ & $\begin{array}{c}\text { Ash } \\
\text { content } \\
(\%)\end{array}$ \\
\cline { 2 - 9 } 1 & 20.43 & 7.93 & 1.33 & 5.98 & 22.17 & 5.81 & 54.86 & 12.67 \\
2 & 21.83 & 8.28 & 1.83 & 5.92 & 21.01 & 6.70 & 48.66 & 13.44 \\
3 & 22.83 & 8.40 & 1.66 & 6.39 & 22.66 & 6.90 & 47.33 & 14.14 \\
4 & 10.50 & 8.00 & 2.50 & 6.40 & 15.01 & 6.02 & 67.50 & 12.61 \\
5 & 26.01 & 8.75 & 1.50 & 7.55 & 8.16 & 7.05 & 59.50 & 12.57 \\
6 & 30.30 & 8.27 & 2.30 & 6.24 & 11.12 & 6.37 & 52.50 & 12.76 \\
\hline
\end{tabular}

The results of orthogonal experiment is denoted in Table 4. Product 1 and Product 2 are separately one section and two sections of large particle size semi-coke after smash. Product 3 is the large particle size semi-coke after classification while Product 4 is collected by the dust catcher. As Product 1 just experiences one section of smash, the dissociation is insufficient, which results in the ash content of Product 1 is higher than Product 2 and Product 3. Thanks to the twice smash and the classification of Product 3, the ash content of Product 2 is slightly lower than Product 3 while decreasing apparently relative to Product 1 . The ash content of Product 4 is higher than the other three products because of the classification and fine particle size.

Table 5 Results of the range analysis

\begin{tabular}{|c|c|c|c|}
\hline \multirow{2}{*}{ Parameters } & A & $\mathrm{B}$ & $\mathrm{C}$ \\
\hline & 1 & 2 & 3 \\
\hline I & 6.25 & 6.09 & 5.92 \\
\hline II & 6.46 & 6.80 & 6.88 \\
\hline III & 6.71 & 6.54 & 6.64 \\
\hline $\mathrm{R}$ & 0.46 & 0.71 & 0.96 \\
\hline Optimum & A1 & B1 & $\mathrm{C} 1$ \\
\hline Impact degree & & $\mathrm{C}>\mathrm{B}>\mathrm{A}$ & \\
\hline
\end{tabular}

Table 5 reveals the results of range analysis among parameter $\mathrm{A}, \mathrm{B}$ and $\mathrm{C}$ in Table 3 . The range of parameter $\mathrm{C}$ is large than others, which indicates that the air volume of the blower occupies the prominent influence on the ash content of refined coal. Furthermore, the speed of classifier (parameter B) also has a significant impact on the ash content even though it is lower than the parameter C. Additionally, Table 5 also demonstrates that the optimize condition of separating the Shenfu semi-coke using CM-41 impact smash is $2900 \mathrm{r} / \mathrm{min}$ of the crusher, $700 \mathrm{r} / \mathrm{min}$ of the classifier and $0.5 Q \mathrm{~m}^{3} / \mathrm{min}$ of the air volume of blower.

\section{Laser particle size analysis}

Analysis from Section 3.1 shows the optimal assembly of the ultra-fine smash of semi-coke is $2900 \mathrm{r} / \mathrm{min}$ of the crusher, $700 \mathrm{r} / \mathrm{min}$ of the classifier and $0.5 Q \mathrm{~m}^{3} / \mathrm{min}$ of the air volume. In this section, we use the laser particle analyzer to detect the composition of the four products, and the results illustrated in Figure 3.

Fig. 3 reveals the distribution range of particle size of Product 1 and Product 2 is wider than the others and Product 1 takes up the largest particle size. The $d_{90}$ of Product 1 and Product 2 are $461.0 \mu \mathrm{m}$ and $129.8 \mu \mathrm{m}$, respectively, as the Product 2 experiences two sections of smash, which contributes to the smaller $d_{90}$ against Product 1 . The particle size range of Product 3 and Product 4 is narrowed because of the classification of classifier, and nearly $90 \%$ of the Product 3 is below $70.24 \mu \mathrm{m}$ while $90 \%$ of the Product 4 is below $19.68 \mu \mathrm{m}$. Combining with the experimental results of ash content in Table 4, it can be obtained that minerals in the semi-coke are concentrated in the fine 
particle products, which indicates that minerals are easier to be smashed compared with the organic matter.
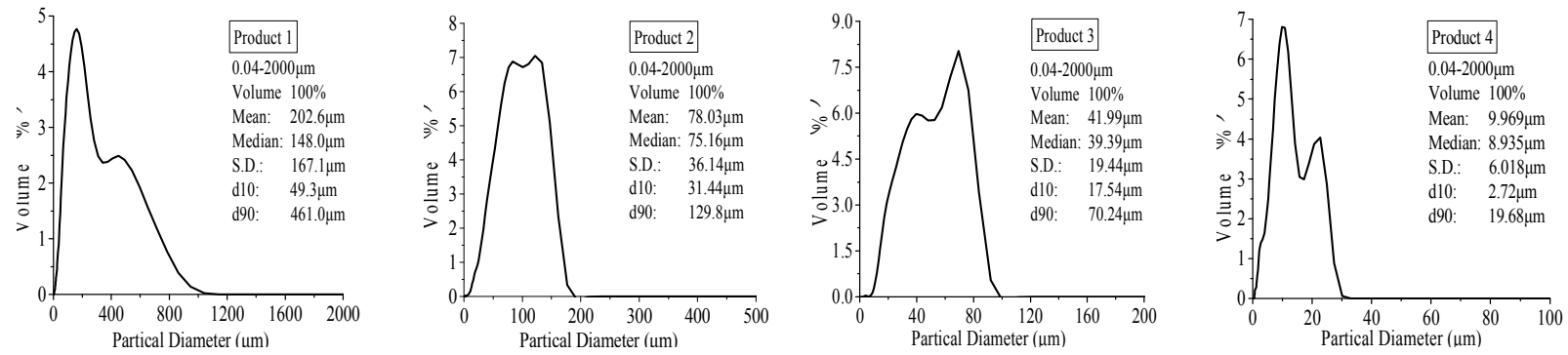

Figure 3 Particle size analysis of the four products

\section{Analysis of the oil absorption}

Test results of the oil absorption exhibited in Table 6 shows that the oil absorption of the derivate four products is apparently higher than that of the raw semi-coke and the value of oil absorption increase with the decreasing particle size, which indicates that the specific surface area increased after the mash of semi-coke powder and the technology of ultra-fine smash and classification can change the surface characteristics of semi-coke. Investigating the potential value and broadening the utilized field of semi-coke is meaningful to the development of coal industry and environment.

Table 6 Oil absorption of the semi-coke products

\begin{tabular}{cccccc}
\hline Product & Raw semi-coke & Product 1 & Product 2 & Product 3 & Product 4 \\
\hline Oil absorption $\left(0.01 \mathrm{~mL} \cdot \mathrm{g}^{-1}\right)$ & 46.69 & 53.28 & 60.54 & 62.97 & 65.36 \\
\hline
\end{tabular}

\section{Conclusion}

(1) The ash content of Shenfu semi-coke powder decreases from $10.99 \%$ to $5.81 \%$ after the smash of CM-41 impact crusher, which indicates the technology of ultra-fine smash has remarkable effect on the decline of ash content.

(2) The minerals in the semi-coke are easier to be smashed through the relation of ash content and particle size.

(3) The specific surface area of the semi-coke powder changes prominently with the smashing of CM-41 impact crusher, which reveals that the semi-coke has higher porosity after ultra-fine smash.

(4) The technology of ultra-fine smash and classification with low energy consumption and simple process can effectively reduce the ash content and dissociation of the semi-coke, which indicates a direction to the industrial utilization of semi-coke and provides a solution to solve the technical difficulties of the semi-coke industry.

\section{References}

[1] Huiqing Sun, Sijian Qu, Libin Wang. Present situation of the semi-coke production and utilization [J]. Clean Coal Technology, 2008, 6: 62-65.

[2] Baoqi Ma, Xiongwei Luo. The Developing Trend of China's semi-coke industry [J].Coal Processing and Comprehensive Utilization, 2014, 4: 22-26.

[3] Jinyuan Lin. Application of Semi-Coke in Calcium Carbide Production [J].Chemical techno-economics, 2004, 22(12):23-25. 
[4] Dongyin Wu, Ansheng Feng, Min Wei, et.al. The Present Status and Development Trend of the Ultrafine Crush Technology [J].Conservation and utilization of mineral resources, 2004, 12: 48-52.

[5] Yan Wu. Study on selective grinding and separation of ultra-low ash Taixi anthracite [D]. Xi' an University of Science and Technology, 2012.

[6] Chenglin Sun. Application of Impacting Disintegrator in the Super Fine Comminuting [J]. Sulphur Phosphorus \& Bulk Materials Handling Related Engineering, 2001, 6: 31-38.

[7] Yingbo Zhu. Mechanism of Comminution and Purification of CM-51 High Speed Impact Ultrafine Comminuter [J]. Conservation and utilization of mineral resources, 2000, 4: 39-42. 